\title{
A New Neolignan and Antioxidant Phenols from Nectandra grandiflora
}

\author{
Alan B. Ribeiro ${ }^{a}$, Vanderlan da S. Bolzani ${ }^{a}$, Massayoshi Yoshida ${ }^{b, c}$, Leonardo S. Santos ${ }^{d}$, Marcos N. \\ Eberlin $^{d}$ and Dulce H. S. Silva ${ }^{*, a}$ \\ ${ }^{a}$ Instituto de Química, Universidade Estadual Paulista, CP 355, 14801-900 Araraquara - SP, Brazil \\ ${ }^{b}$ Instituto de Química, Universidade de São Paulo, CP 26077, 05513-970 São Paulo - SP, Brazil \\ ${ }^{c}$ Instituto de Pesquisas da Amazônia, CP 476, 69083-000 Manaus - AM, Brazil \\ ${ }^{d}$ Instituto de Química, Universidade Estadual de Campinas, CP 6154, 13084-971 Campinas - SP, Brazil
}

\begin{abstract}
O extrato etanólico das folhas de Nectandra grandiflora coletadas na Mata Atlântica, Brasil, mostrou atividade antioxidante frente ao $\beta$-caroteno em teste usando cromatografia em camada delgada. O fracionamento biomonitorado levou ao isolamento do ácido protocatecuico e de dois flavonóides glicosilados: afzelina e quercetrina, os quais exibiram atividade sequestradora de radicais livres frente ao DPPH $\left(\triangle \mathrm{A} 32,16\right.$ e $73 \%$ a $\left.50 \mu \mathrm{mol} \mathrm{L}^{-1}\right)$ e foram comparados aos antioxidantes comerciais rutina $\left(81 \%\right.$ a $\left.50 \mu \mathrm{mol} \mathrm{L}^{-1}\right)$ e BHT $\left(9 \%\right.$ a $\left.50 \mu \mathrm{mol} \mathrm{L}^{-1}\right)$, usados como substâncias de referência. Além disso, três neolignanas inativas, incluindo a nova neolignana biciclo[3.2.1] octânica 2'-oxo-piperol B, foram obtidas e caracterizadas por métodos espectrométricos.
\end{abstract}

The EtOH crude extract from the leaves of Nectandra grandiflora collected in the Atlantic Forest, Brazil, showed antioxidant activity towards $\beta$-carotene in a TLC assay. The bioassay-guided fractionation led to the isolation of protocatechuic acid and two flavonol glycosides: afzelin and quercetrin, which showed free radical scavenging activity towards DPPH $(\triangle \mathrm{A} 32,16$ and $73 \%$ at 50

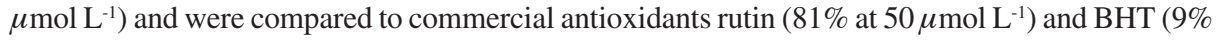
at $\left.50 \mu \mathrm{mol} \mathrm{L}^{-1}\right)$, used as standard compounds. Additionally, three inactive neolignans, including the new bicycle[3.2.1] octane neolignan 2'-oxo-piperol B were obtained and characterized by spectrometric methods.

Keywords: Nectandra grandiflora, Lauraceae, neolignan, flavonoid, radical scavenging activity, antioxidant

\section{Introduction}

Nectandra grandiflora Nees is a tree belonging to Lauraceae family, which is known for economically important species such as Aniba roseodora ("pau-rosa"), the main source of sesquiterpene (linalool)-rich essential oil used in perfumery; and species with scented leaves and bark such as Laurus nobilis (bay leaves) and Ocotea odorifera (Brazilian cinnamon), widely used as condiments. ${ }^{1-3}$ Lignans and neolignans are important classes of secondary metabolites occurring in Lauraceae species, which include several medicinally important closely related compounds as the anti-mitotic podophyllotoxin, extracted from Podophyllum peltatum (Berberidaceae), used in the preparation of the antitumoral

*e-mail: dhsilva@iq.unesp.br lignans etoposide and teniposide, and the antioxidant nordihydroguaiaretic acid (NDGA), obtained from Larrea tridentata (Zygophyllaceae). ${ }^{4}$

Nectandra species are extensively used in folk medicine due to their antirrheumatic, digestive and diuretic properties. ${ }^{5}$ Some of the claimed medicinal properties have been substantiated by studies, e.g. on Nectandra salicifolia, which showed antifungal and vascular muscle relaxing properties, ${ }^{6}$ in addition to antimalarial activity due to the presence of the alkaloid costaricin in its bark extract. ${ }^{7}$ Previous work on $N$. grandiflora evidenced the presence of aporphine alkaloids and antitumoral activity in its bark extract. ${ }^{8}$

A number of pathologies are known to be ultimately associated with the imbalance of pro and antioxidant factors in living systems. Exogenous antioxidant compounds may therefore exert beneficial actions upon 
systems which have been deprived from sufficient amounts of endogenous antioxidants as in some cardiovascular diseases, tumors, inflammation, ulcer and aging. ${ }^{9}$

As part of our ongoing projects aiming the phytochemical investigation of São Paulo State flora, ${ }^{10-12}$ the EtOH crude extract from leaves of $N$. grandiflora collected at Jureia State Park, Atlantic Forest, have been subjected to bioassay-guided fractionation using the $\beta$-carotene test on TLC for the detection of antioxidant compounds. ${ }^{13}$ Pure compounds isolated from this extract were further evaluated for their free radical scavenging activity towards the stable free radical DPPH and compared to standard compounds rutin and BHT. ${ }^{11,14}$ Non-active fractions were also investigated and afforded the benzofuran neolignan burchellin and two bicyclooctane[3.2.1] neolignans: piperol $\mathrm{B}$ and the new 2'-oxo-piperol B.

\section{Results and Discussion}

The EtOH crude extract of $N$. grandiflora leaves was successively partitioned with organic solvents affording hexane, $\mathrm{CHCl}_{3}, \mathrm{EtOAc}$ and $\mathrm{MeOH}$ extracts. The TLC test using $\beta$-carotene as revealing agent indicated the presence of antioxidant compounds in the EtOAc and $\mathrm{MeOH}$ fractions. Chromatographic fractionation of these extracts led to the isolation of protocatechuic acid (6) and flavonol glycosides afzelin (4) and quercetrin (5), which were
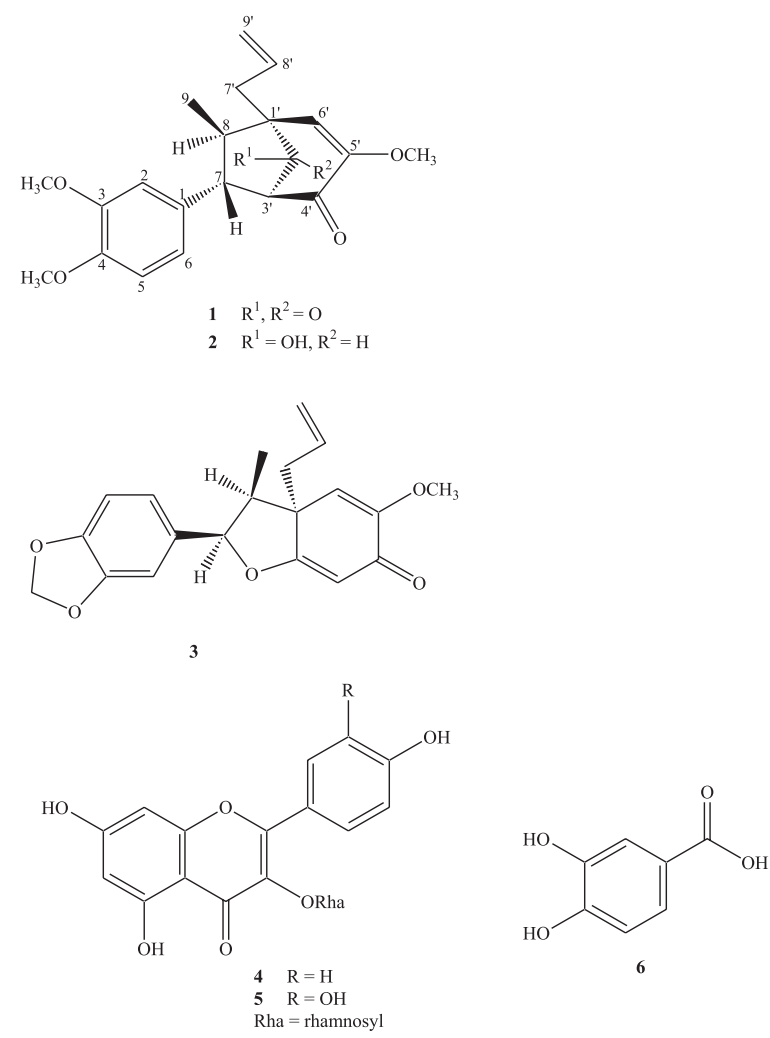

identified through analyses of their MS and NMR spectra and comparison with literature data. ${ }^{15,16}$ Fractionation of the $\mathrm{CHCl}_{3}$ extract led to the isolation of neolignans 1-3.

Compound 1 was obtained as a light brown viscous oil and its ${ }^{13} \mathrm{C}$ NMR spectrum showed 12 signals for $\mathrm{sp}^{2}$ carbons and 9 signals for $\mathrm{sp}^{3}$ carbons, including three signals at $c a$. $\delta 56$, assigned to three methoxy groups on $\mathrm{sp}^{2}$ carbons (Table 1). These data combined with HRMS analysis in the positive ion mode $\left[\left(\mathrm{C}_{21} \mathrm{H}_{24} \mathrm{O}_{5},(\mathrm{M}+1)^{+\cdot} 357\right.\right.$; expanded to $\mathrm{C}_{18} \mathrm{H}_{15} \mathrm{O}_{2} \cdot\left(\mathrm{OCH}_{3}\right)_{3}$ ] suggested compound $\mathbf{1}$ is a bicarbonyl neolignan, with ${ }^{13} \mathrm{C}$ NMR signals for $\mathrm{C}=\mathrm{O}$ groups at $\delta 190.5$ and $\delta$ 203.0.

Table 1. NMR spectral data for compound $\mathbf{1}^{\text {a }}$

\begin{tabular}{|c|c|c|c|}
\hline position & $\delta_{\mathrm{H}}{ }^{\mathrm{b}}$ & $\delta_{\mathrm{C}}{ }^{\mathrm{c}}$ & HMBC \\
\hline 1 & - & $134.3 \mathrm{~s}$ & - \\
\hline 2 & $6.47 \mathrm{~d}(2)$ & $110.6 \mathrm{~d}$ & $\mathrm{C}-7$ \\
\hline 3 & - & $148.6 \mathrm{~s}$ & - \\
\hline 4 & - & $149.6 \mathrm{~s}$ & - \\
\hline 5 & $6.71 \mathrm{~d}(8)$ & $111.8 \mathrm{~d}$ & - \\
\hline 6 & $6.55 \mathrm{dd}(2$ e 8$)$ & $119.5 \mathrm{~d}$ & - \\
\hline 7 & 2.48 br d (7) & $50.2 \mathrm{~d}$ & $\begin{array}{l}\text { C-1, C-2, C-9 } \\
\text { C-4', C-2, }\end{array}$ \\
\hline 8 & 2.08 quint (7) & $47.1 \mathrm{~d}$ & C-1, C-6 \\
\hline 9 & $0.99 \mathrm{~d}(7)$ & $14.3 \mathrm{q}$ & C-7, C-8 \\
\hline $1^{\prime}$ & - & $56.1 \mathrm{~s}$ & - \\
\hline $2^{\prime}$ & - & $203.0 \mathrm{~s}$ & - \\
\hline $3^{\prime}$ & $3.49 \mathrm{~d}(1)$ & $70.5 \mathrm{~d}$ & $\begin{array}{l}\text { C-1, C-2', C-4', } \\
\text { C-5, }\end{array}$ \\
\hline $4^{\prime}$ & - & $190.5 \mathrm{~s}$ & - \\
\hline $5^{\prime}$ & - & $152.7 \mathrm{~s}$ & - \\
\hline $6^{\prime}$ & $5.72 \mathrm{~s}$ & $118.2 \mathrm{~d}$ & $\mathrm{C}-7$ \\
\hline $7^{\prime}$ & 2.48 br d (8) & $35.6 \mathrm{t}$ & C-2', C-8', C-9' \\
\hline $8^{\prime}$ & $5.89 \mathrm{~m}$ & $133.3 \mathrm{~d}$ & - \\
\hline 9'a & $5.08 \mathrm{br} \mathrm{d}(11.5)$ & $119.3 \mathrm{t}$ & - \\
\hline $9 ’ b$ & 5.14 br d (14.5) & & - \\
\hline $\mathrm{OMe}-3$ & $3.65 \mathrm{~s}$ & $55.9 \mathrm{q}$ & - \\
\hline OMe-4 & $3.77 \mathrm{~s}$ & $56.1 \mathrm{q}$ & $\mathrm{C}-4$ \\
\hline $\mathrm{OMe}-5$ & $3.78 \mathrm{~s}$ & $57.6 \mathrm{q}$ & $\mathrm{C}-5$ \\
\hline
\end{tabular}

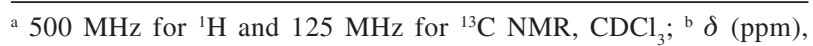
multiplicities, $J(\mathrm{~Hz}) ;{ }^{\mathrm{c}}$ Assignments were based on HMQC experiment and multiplicities were mostly taken from a DEPT $135^{\circ}$ experiment.

The ${ }^{1} \mathrm{H}$ NMR spectrum of compound $\mathbf{1}$ showed three broad doublets at $\delta 2.48, \delta 5.08$ and $\delta 5.14$, and one multiplet at $\delta 5.89$ assigned to hydrogens of an allyl moiety. Additionally, a doublet at $\delta 0.99(3 \mathrm{H}-9)$ and a quintuplet at $\delta 2.08$ (H-8) indicated compound $\mathbf{1}$ is a guianin type bicyclooctane neolignan. ${ }^{17,18}$ The absence of a doublet at ca. $\delta 5.90$ for an oxybenzylic hydrogen of the related benzofuran type neolignans, gave additional support to this proposal. Its relative stereochemistry was deduced from the absence of anisotropy from the aromatic ring on the deshielded H-9 $(\delta$ 0.99) evidencing a trans relationship between methyl group C-9 and the aromatic ring. ${ }^{17,18}$ 
Moreover, the bicycle bridge associated with the guianin type configuration of $\mathbf{1}$ is evidenced by the absorption of $\mathrm{H}$ 6 ' at $\delta$ 5.72. Further analysis of NMR spectra and comparison with literature data for other guianin-type compounds suggested the presence of an $\alpha, \beta$-unsaturated carbonyl moiety and an additional carbonyl (C-2', $\left.v 1760 \mathrm{~cm}^{-1}\right)$ in the bicyclic moiety. ${ }^{17,18} \mathrm{HMQC}$ correlations allowed the complete assignment of hydrogen signals to carbons; and HMBC correlations of C-2' to H-7, H-3' and H-7'; and C-4' to $\mathrm{H}-7$ and $\mathrm{H}-3$ ' supported the position of carbonyl groups at C-2' and C-4' in the bicyclic moiety, respectively (Figure 1). This spectrum also showed correlations of C-5' to H-3'; C-7' to H-6'; and C-1 to H-7, H-8 and H-3', which supported the position of one methoxyl at C-5', the allyl group at C-1' and aromatic ring at C-7. Additional cross-peaks in the HMBC spectrum gave support to the proposed structure for compound 1 (Figure 1).

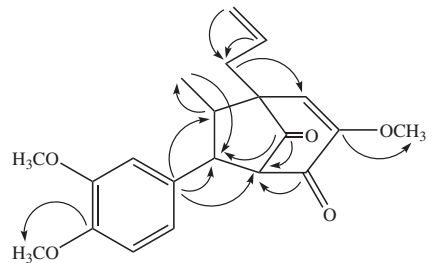

Figure 1. Selected HMBC correlations for compound 1.

ESI(+)-MS/MS experiments for the protonated molecule of $\mathrm{m} / \mathrm{z} 357$ with dissociation induced by collisions with argon provides further structural characterization as dissociation forms major ionic fragments of $m / z 316$ (24), 341 (8), and 301 (22) owing to the losses of an allyl, methyl and allyl plus methyl radicals, in addition to a fragment ion of $m / z 151$ (9), assigned to the dimethoxytropilium ion. Additionally, the protonated 1, of $m / z 357$, dissociates by the loss of a neutral molecule of 1,2-dimethoxybenzene to yield the ion of $\mathrm{m} / \mathrm{z} 219$ (Figure 2), which likely rearranges to form an acylium ion that subsequently loses a neutral $\mathrm{C}_{3} \mathrm{H}_{4}$ allene to yield an ion of $m / z$ 179. Additional data from a LRMS experiment showed the base peak of $\mathrm{m} / \mathrm{z} 179$ and peaks at 357, 325, 316 and 219 (see Experimental section), which gave support to the structure proposed for compound $\mathbf{1}$. These data are fully consistent with the new bicyclooctane neolignan 1 , which is therefore assigned as $\left(7 S^{*}, 8 R^{*}, 1^{\prime} R^{*}\right.$, $\left.3^{\prime} R^{*}\right)$-3,4,5' -trimethoxy-3,7' -cyclo-8, 1'-neolig-8'-ene2,4'(3'H)-dione.

Compound 2 was identified as the bicycle [3.2.1] octane neolignan piperol $\mathrm{B}$ and compound $\mathbf{3}$, as the benzofuran neolignan burchellin, previously isolated from Piper betle and Aniba burchelli, respectively. ${ }^{19,20}$ Compound $\mathbf{2}$ is a

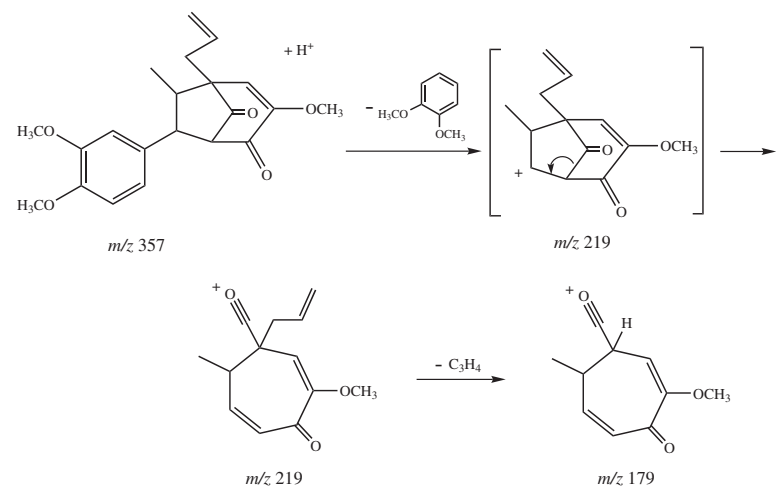

Figure 2. Dissociation routes to selected ESI(+)-MS/MS ionic fragments for compound $\mathbf{1}$.

guianin type and compound $\mathbf{3}$ is a porosin type neolignan and their identification was based on extensive analyses of NMR data as well as on comparison with literature data for guianin, porosin and ferrearin type neolignans, which are widely distributed in Lauraceae species. ${ }^{21}$

The antiradicalar activity of compounds 1-6 has been evaluated towards the stable free radical DPPH, which exhibits an absorption maximum at $517 \mathrm{~nm}$, evidencing prominent activities of compounds 4-6 (Figure 3 ) and poor activities for compounds 1-3. The absence of phenolic hydroxyls in the latter renders them less effective in promoting DPPH reduction, therefore appearing as poor radical scavengers. The free radical scavenging activity of flavonoids and other phenols is mostly due to their aromatic hydroxy groups, which confer great stability to the phenolic radical as soon it is formed, after one hydrogen radical donation to DPPH. The stronger activity of compound $\mathbf{5}$ when compared to compounds $\mathbf{4}$ and $\mathbf{6}$ is probably due to the catechol moiety in the $\mathrm{B}$ ring of quercetrin along with its extended conjugation through the $\alpha, \beta$-unsaturated carbonyl system on the $\mathrm{C}$ ring, which are some of the major structural features associated with antioxidant activity of flavonoids. ${ }^{22}$ The comparison with standard compound rutin $\left(\Delta \mathrm{A}=81 \%\right.$ at $\left.50 \mu \mathrm{mol} \mathrm{L}^{-1}\right)$ evidences the reported major roles of some structural

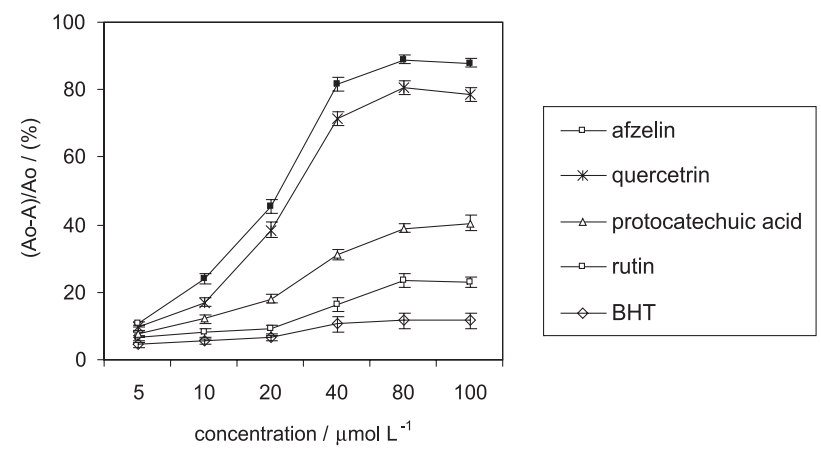

Figure 3. Free-radical scavenging activity of compounds 4-6 and reference compounds BHT and rutin. 
features of flavonoids as the catechol moiety present in the $\mathrm{B}$ ring and the $\mathrm{C} 2-\mathrm{C} 3$ double bond for the enhancement of the free radical scavenging activity. ${ }^{22}$ On the other hand, the synthetic antioxidant $\mathrm{BHT}\left(\Delta \mathrm{A}=9 \%\right.$ at $\left.50 \mu \mathrm{mol} \mathrm{L}^{-1}\right)$ exhibited the weakest antiradicalar activity as expected, due to its slow reaction rate with DPPH. ${ }^{23}$

\section{Experimental}

\section{General experimental procedures}

Silica gel (Merck 230-400 Mesh) and Sephadex LH-20 (Pharmacia) were used for all column chromatography separations unless otherwise stated. HPLC separations were performed on a Waters Prep LC 4000 System and C-18 Luna (Phenomenex) columns (4.6 mm and 20mm i.d. for analytical and preparative columns, respectively) and pre-columns were used. All solvents (Merck or Malinckrodt) were of analytical or HPLC grade. ${ }^{1} \mathrm{H}$ and ${ }^{13} \mathrm{C}$ NMR spectra were recorded on a Varian Unity 500 spectrometer at 500 and $125 \mathrm{MHz}$, respectively, using $\mathrm{CDCl}_{3}$ or DMSO-d $\mathrm{d}_{6}$ as solvent and TMS as reference. IR spectra were obtained on a Nicolet spectrometer. Low resolution ESI(+)-MS were recorded on a VG Platform II spectrometer. High resolution ESI(+)-MS analysis were performed on a hybrid double quadrupole (Qq) and orthogonal time-of-flight (Tof) mass spectrometer (Qtof, Micromass UK) operating at 7.000 resolution and mass accuracy of $10 \mathrm{ppm}$. The temperature of the nebulizer was $50^{\circ} \mathrm{C}$. The ESI and mass spectrometer were operated in the positive ion mode. The cone and extractor potential were set to 40 and $0 \mathrm{~V}$, respectively. The $\mathrm{m} / z$ scan range was from 50 up to 1000. Tandem mass spectrometric [ESI(+)MS/MS] experiments were performed using the product ion scan mode via Q1 mass selection of the desirable product ion, $\mathrm{q} 2$ collision-induced dissociation (CID) with $\mathrm{N}_{2}$, and orthogonal TOF mass analysis of the CID ionic fragments. The collision energy ranged from 15 to $25 \mathrm{eV}$, depending on the dissociation lability of the precursor ion.

\section{Plant material}

Nectandra grandiflora leaves were collected in JureiaItatins State Park, Atlantic Forest, Brazil, and identified by Dr. Ines Cordeiro. The voucher specimens (number: Moraes 05) were deposited at Herbarium of Instituto de BotânicaSEMA, SP, Brazil.

\section{Extraction and isolation}

Dried and ground leaves $(2.0 \mathrm{~kg})$ were extracted with ethanol at r.t. and afforded a dark green EtOH extract (5.0 g) after solvent evaporation under vacuum. Partition of the EtOH extract with organic solvents gave the hexane (0.6g), $\mathrm{CHCl}_{3}(1.6 \mathrm{~g})$, EtOAc (0.5 g) and hydroalcoholic $(2.3 \mathrm{~g})$ extracts after solvent evaporation. MPLC on silica gel of the $\mathrm{CHCl}_{3}$ extract (1.6 g, hexane/EtOAc gradient) gave 15 pooled fractions (A1-A15). Fraction A2 (41.0 mg) was submitted to preparative TLC $\left(\mathrm{CHCl}_{3}\right.$ /acetone/HOAc 90:9:1) and gave compound 2 (12.2 mg). Fraction A3 (32.1 $\mathrm{mg}$ ), obtained from the elution with hexane/EtOAc 4:1, was further purified by preparative TLC $\left(\mathrm{CHCl}_{3}\right.$ /acetone/ HOAc 90:9:1) and gave compound 1 (6.8 mg). Fraction A6 $(88.1 \mathrm{mg})$ was recrystallized in $\mathrm{MeOH}$ to afford compound 3 (25.5 mg). CC on Sephadex LH-20 of the EtOAc fraction (200.0 mg) eluted with $\mathrm{MeOH}$ resulted in 42 subfractions which were pooled after TLC analysis (B1B4). Fr. B2 (38.7 mg) was submitted to preparative TLC $\left(\mathrm{CHCl}_{3} / \mathrm{MeOH} / \mathrm{H}_{2} \mathrm{O} / \mathrm{HOAc}\right.$ 79:18:2:1) and gave compound $4(7.1 \mathrm{mg})$. Purification of fraction B3 (45.1 mg) by preparative TLC $\left(\mathrm{CHCl}_{3} / \mathrm{MeOH} / \mathrm{H}_{2} \mathrm{O} / \mathrm{HOAc} 36: 12: 1: 1\right)$ afforded compound $5(14.0 \mathrm{mg})$. The hydroalcoholic fraction $(200.0 \mathrm{mg}$ ) was submitted to CC on Sephadex LH-20 eluted with $\mathrm{MeOH}$ resulting in 10 fractions (C1C10). Purification of fraction C-8 (37.7 mg) by RP-HPLC (C18 Luna-Phenomenex column, $\mathrm{MeOH} / \mathrm{H}_{2} \mathrm{O} / \mathrm{HOAc}$ $55: 43: 2,8 \mathrm{~mL} \mathrm{~min}^{-1}$, detection at $280 \mathrm{~nm}$ ) gave compound $6(8.1 \mathrm{mg})$.

\section{Bleaching of $\beta$-carotene on TLC plates}

Samples were eluted on TLC plates which were then dried and sprayed with $0.02 \%$ solution of $\beta$-carotene (Aldrich) in $\mathrm{CH}_{2} \mathrm{Cl}_{2}$. Plates are placed under natural light until discoloration of background. The remaining yellow spots indicate the presence of antioxidants. ${ }^{13}$

\section{Reduction of 2,2-diphenyl-1-picrylhydrazyl radical (DPPH)}

The free radical scavenging capacities of the isolates and standard compounds rutin and BHT were evaluated from their ability to reduce the free radical 2,2-diphenyl1-picrylhydrazyl (DPPH). Each compound (1 mg) was solubilized in methanol $(10 \mathrm{~mL})$ to yield a stock solution. Several dilutions of each compound from $5 \mu \mathrm{mol} \mathrm{L}^{-1}$ to $100 \mu \mathrm{mol} \mathrm{L}{ }^{-1}$ were then prepared in methanol and to each sample a solution of DPPH $(0.004 \%)$ was added. Absorbance at $517 \mathrm{~nm}$ was determined after $30 \mathrm{~min}$ on a Milton Roy 20D spectrophotometer and the percentage of activity was calculated as $\Delta \mathrm{A}=(\mathrm{Ao}-\mathrm{A}) / \mathrm{Ao} .{ }^{11,14}$

(7S $*, 8 \mathrm{R} *, 1$ ' $\mathrm{R} *, 3$ ' $\mathrm{R} *$ ) -3,4,5'-trimethoxy-3,7'-cyclo8,1'-neolig-8'-ene-2,4'(3'H)-dione (1). Light brown oil. 
$\operatorname{IR(film)~} v_{\max } / \mathrm{cm}^{-1}: 1760,1660,1620,1600,1509,1460$; HRMS [ESI(+)-MS]: $\mathrm{C}_{21} \mathrm{H}_{25} \mathrm{O}_{5}[\mathrm{M}+\mathrm{H}]^{+} m / z$, calc. 357.1702, found 357.1614; tandem ESI(+)-MS-MS from selected ion of $m / z, 357, m / z(\%): 316$ (24), 341 (8), 301 (22), 219 (42), 179 (100), 151 (9). LRMS [ESI(+)-MS], $m / z(\%): 357$ (41), 325 (18), 316 (68), 219 (42), 179 (100); ${ }^{1} \mathrm{H}$ and ${ }^{13} \mathrm{C}$ NMR spectral data are given in Table 1 .

\section{Acknowledgements}

This work was supported by the State of São Paulo Research Foundation (FAPESP) within the BIOTA/FAPESP - The Biodiversity Virtual Institute Program (www.biota.org.br), CNPq (Conselho Nacional de Desenvolvimento Científico e Tecnológico - Brazil) and CAPES. A.B.R. thanks CAPES for providing him a scholarship.

\section{References}

1. Naves, Y. R.; Bull. Soc. Chim. Fr. 1956, 2, 292.

2. Hokwerda H.; Bos R; Tattje D. H. E.; Malingre T. M.; Planta Med. 1982, 44, 116.

3. Gottlieb O. R.; Magalhães M. T.; J. Org. Chem. 1959, 24, 2070.

4. MacRae, W. D.; Towers, G. H. N.; Phytochemistry 1984, 23, 1207.

5. Correa, P. M.; Dicionário de Plantas Úteis do Brasil e das Exóticas Cultivadas, Imprensa Nacional: Rio de Janeiro, Brasil. 1984.

6. Slish, D. F.; Ueda, H.; Arvigo, R.; Balick, M. J.; J. Ethonopharmacol. 1999, 66, 159.

7. Bohlke, M.; Guinaudeau, H.; Angerhofer, C. K.; Wongpanich, V.; Soejarto, D. D.; Farnsworth, N. R.; Mora, G. A.; Poveda, L. J.; J. Nat. Prod. 1996, 59, 576.

8. Moreno, P. R. H.; von Poser, G. L.; Rates, S. M. K.; Yoshida, M.; Gottlieb, O. R.; Souza, I. A.; Henriques, A. T.; Int. J. Pharmacogn. 1993, 31, 189.
9. Gordon, M. H.; Nat. Prod. Rep. 1996, 13, 265.

10. Castro-Gamboa, I.; Cavalheiro, A. J.; Cardoso, C. L.; Silva, D. H. S.; Furlan, M.; Bolzani, V. S. J. Braz.Chem. Soc. 2003, 14, 771.

11. Pauletti., P. M.; Castro-Gamboa, I.; Silva, D. H. S.;Young, M. C. M.; Tomazela, D. M.; Eberlin, M. N.; Bolzani, V. S.; J. Nat. Prod. 2003, 66, 1384.

12. Ribeiro, A. B.; Silva, D. H. S.; Bolzani, V. S.; Eclet. Quim. 2002, 27, 35 .

13. Pratt, D.E.; Miller, E. E.; J. Am. Oil Chem. Soc. 1984, 61, 1064.

14. Blois, M. S.; Nature 1958, 181, 1199.

15. Agrawal, P. K.; Bansal, M. C. In Carbon-13 NMR of Flavonoids; Agrawal, P. K., ed., Elsevier: Amsterdan, 1989, p. 283.

16. Harborne, J. B.; Williams, C. A. In The Flavonoids: Advances in Research; Harborne, J. B.; Mabry, T. J., eds., Chapman \& Hall: London, 1982, p. 261.

17. David, J. M.; Yoshida, M.; Gottlieb, O. R.; Phytochemistry 1994, 36, 491.

18. Lordello, A. L. L.; Yoshida, M.; Phytochemistry 1997, 46, 741.

19. Zeng, H.; Jiahg, Y.; Cai, D.; Bian, J.; Long, K.; Chen, Z; Planta Med. 1997, 63, 296.

20. Lima, O. A.; Gottlieb, O. R.; Magalhaes, M. T.; Phytochemistry 1972, 11, 2031.

21. Agrawal, P. K.; Thakur, R. S.; Magn. Res. Chem. 1985, 23, 389.

22. van Acker, S. A. B. E.; Vanden Berg, D.-J.; Tromp, M. N. J. L.; Griffioen, D. H.; Van Bennekom, W. P.; Van der Vijgh, W. J. F.; Bast, A.; Free Rad. Biol. Med. 1996, 20, 331.

23. Bondet, V.; Brand-Williams, W.; Berset, C.; Lebensm. Wissenschaft. Technol. 1997, 30, 609.

Received: March 9, 2004

Published on the web: March 4, 2005

FAPESP helped in meeting the publication costs of this article. 